2. Fay, T.J.A.N.P., Atypical neuralgia. 1927. 18: p. 309-315.

3. Farage, L., et al., Idiopathic inflammatory pseudotumor of the carotid sheath.Arq Neuropsiquiatr, 2007. 65(4b): p. 1241-4.

4. The International Classification of Headache Disorders: 2nd edition. Cephalalgia, 2004. 24 Suppl 1: p. 9-160.

5. Burton, B.S., et al., MR Imaging of Patients with Carotidynia. 2000. 21(4): p. 766-769.

6. Lecler, A., et al., TIPIC Syndrome: Beyond the
Myth of Carotidynia, a New Distinct Unclassified Entity. 2017. 38(7): p. 1391-1398.

7. Robertson, V., et al., A Systematic Review and Meta-Analysis of the Presentation and Surgical Management of Patients With Carotid Body Tumours. Eur J Vasc Endovasc Surg, 2019. 57(4): p. 477-486.

8. Đoàn Quốc Hưng, Pham Tuấn Cảnh, Chử Vân Khánh. Chẩn đoán và điều trị u cuộn cảnh vùng đầu cổ. Tạp chí phẫu thuật tim mạch và lồng ngực Việt Nam 8/2017, 17: 33-38.

\title{
TÁC DỤNG ĐÎ̀̀U TRI ĐAU THẮT LƯNG DO THOÁI HÓA CộT SỐNG BẰNG ĐIỆN CHÂM KẾT HỢP SIÊU ÂM ĐIỀU TRI
}

\section{TÓM TẮT}

Mục tiêu: Đánh giá tác dụng giảm đau và cải thiện vận động cột sống của điện châm kết hợp siêu âm điều trị trên bệnh nhân đau thắt lưng do thoái hóa cột sống. Đối tượng và phương pháp: 60bệnh nhân tuổi trên 20được chẩn đoán đau thắt lưng do thoái hóa cột sống, không phân biệt giới tính, nghề nghiêp, tình nguyến tham gia nghiên cứu. Nhóm nghiển cứu điều trị bằng điện châm kết hợp siêu âm điêu trị, nhóm đối chứng điều trị bằng điện châm đơn thuần.So sánh kết quả trước vàsau điều trị. Kết quả: Điện châm kết hợp siêu âm điều trịcó hiệu quả tốt trong điều trị đau thắt lựng do thoái hóa cột sống, $80 \%$ đat kết quả tốt. Điểm VAS giảm từ 6,32 (điểm) trước điều trị xuống còn 0,70 (điểm) sau điều trị; độ giãn cột sống thắt lưng tăng từ $1,18(\mathrm{~cm})$ trước điều trị lên $3,83(\mathrm{~cm})$ sau điều trị;;tầm vận động cột sống thắt lưng cải thiện tốt hơn có ý nghĩa so với trước điêu trị và tốt hơn so với nhóm đối chứng. Kết luân: Điên châm kết hợp siêu âm điều trịhiệu quả tốt trong điểu trị đau thắt lưng do thoái hóa côtt sống.

Tư khóa: Điện châm, siêu âm điêuu trị, thoái hóa cột sống thắt lưng.

\section{SUMMARY \\ THE EFFECTS OF TREATMENTOF LOW BACK PAIN CAUSED BY DEGENERATIVE SPINEBY ELECTRIC ACUPUNCTURECOMBINED WITH ULTRASOUND TREATMENT}

Objective: To evaluate the pain-relieved effect and improvement in spine motor function of electric acupuncture combined with ultrasound treatmenton the low back pain caused by degenerative spine. Subjects and methods: 60 volunteered patients aged over 20 diagnosed with degenerative spondylosis

\footnotetext{
${ }^{1}$ Bệnh viện Châm cứu Trung ương,

2Viện Y học cổ truyền Quân đội

Chịu trách nhiệm chính: Nguyễn Đức Minh

Email: drminhchamcuu@gmail.com

Ngày nhận bài: 29/4/2021

Ngày phản biên khoa học: 25/5/2021

Ngày duyệt bài: 18/6/2021
}

\section{Nguyễn Đức Minh ${ }^{1}$, Nguyễn Vinh Quốc ${ }^{2}$}

of lumbar spine, regardless of gender or occupation, were participated in the study. Researchers combined using electric acupuncturewithultrasound treatment, while the control group was treated with electric acupuncture only. Comparing the results before and after treatment. Result: The low back pain caused by degenerative spine treating method by using the combination of electric acupuncturewithultrasound treatment worked efficiency, $80 \%$ rate of good results. The VAS score reduced from 6.32 (before the treatment) to 0.70 after the study; the lumbar spinal dilation increased from $1.18 \mathrm{~cm}$ to $3.83 \mathrm{~cm}$ after the treatment; the lumbar spine movementimproved better than before treatment and better than control group, difference was statistically significant. Conclusion: The treating method usingelectric acupuncture withultrasound treatmentis effective in treating low back pain caused by degenerative spine.

Keywords: Electric acupuncture, ultrasound treatment, degenerative lumbar spine

\section{I. ĐĂT VẤN ĐỀ}

Đau thắt lưng do thoái hóa cột sống (THCS) là bệnh lý thường gặp và chiếm tỷ lệ caotrong nhóm các bệnh lý xương khớpvới biểu hiện lâm sàng cơ bản là đau. Bệnh ảnh hưởng tới năng suất lao động, chất lượng cuộc sống và sinh hoạt của người bệnh [1]. Đau thắt lưng do THCS không điêu trị kịp thời hoặc điêuu trị khôngđúng phương pháp có thể để lại những hậu quả nặng nề, gây gánh nặng cho bản thân người bệnh, cho gia đình và xã hội [1],[2]. Do vậy điêu trị hiệu quả bệnh lý này đang là mối quan tâm nghiên cứu của các thây thuốc.

Theo $\mathrm{Y}$ học cổ truyên (YHCT), THCS thắt lưng được biết tới với bệnh danh Yêu thống. Điều trị bệnh lý này có rất nhiều phương pháp mang lại hiệu quả tốt trong đó có các phương pháp điều trị không dùng thuốc[3],[4]...

Điện châm là phương pháp điêu trị có tác dụng giảm đau, giãn cơ thường được các thây thuốc YHCT áp dụng trong điều trị bệnh lý cơ 
xương khớp[3], [4]. Siêu âm điều trị là phương pháp vật lý có tác dụng giảm đau, giãn cơ, giảm phù nề, giảm các triệu chứng viêmcũng được nhiều thâyy thuốc $Y$ học hiện đại sử dụng trong trị liệu bệnh lý cột sông [5], [6]. Để tăng cường hiệu quả điều trị, cải thiện chất lượng sống cho người bệnh, nghiên cứu được thực hiện nhằm muc tiêu đánh giá hiêu quả điêu trị đau thắt lưng do THCS của điện châm kết hợp siêu âm điều tri.

\section{CHẤT LIÊU, ĐỐI TƯợNG VÀ PHƯƠNG PHÁP NGHIÊN CỨU}

\subsection{Chất liệu nghiên cứu}

- Máy siêu âm trị liệu ST-10A do hãng Stratek (Hàn Quốc) sản xuất.

- Máy điện châm M8 do Bệnh viện châm cứu Trung ương sản xuất; Thước đo thang điểm VAS (Visual Analogue Scale)của hãng Astra- Zeneca; Thước đo tầm vận động cột sống, thước dây.

- Kim châm cứu 1 lần các cõ̃, pince, bông, cồn $70^{\circ}$, gel và các dụng cụ cần thiết khác phục vụ yêu câu kỹ thuật.

2.2. Đối tượng nghiên cứu. 60 bệnh nhân (BN) trên 20 tuổi được chẩn đoán đau thắt lưng do THCS [1], không phân biệt giới tính, nghề nghiệp, tình nguyện tham gia nghiên cứu. Điều trị tại Bệnh viện Châm cứu Trung ương/Bộ Y tế từ tháng $6 / 2020$ - tháng 12/2020. Không đưa vào nghiên cứu các $\mathrm{BN}$ có tiền sử dị ứng, suy gan, suy thận, suy tim, đái tháo đường, phụ nữ có thai, lao cột sống, có dị vật kim loại trong cơ thể.

2.3. Phương pháp nghiên cứu. Nghiên cứu tiến cứu, thử nghiệm lâm sàng mở.So sánh kết quả trước và sau điều trị và có nhóm đối chứng. Chọn mẫu có chủ đích theo phương pháp ghép cặp đảm bảo tương đồng về tuổi, giới, nghề nghiệp, tính chất khởi phát, mức độ đau theo thang điểm VAS và các triệu chứng lâm sàng khác. Các BN được chia thành 2 nhóm, mỗi nhóm $30 \mathrm{BN}$ :

- Nhóm đối chứng (NĐC): điều trị đơn thuần bằngđiện châm theo phác đồ châm tả các huyệt Thận du, Đại trường du, Thứ liêu, Trật biên, Yêu dương quan, Giáp tích L1-L5, Hoàn khiêu và châm bình bổ bình tả huyệt Uỷ trung bên đau, thời gian 20 phút/lần $x$ 1lần/ngày $x 20$ ngày[7].

- Nhóm nghiên cứu (NNC): điều trị như NĐCkết hợp siêu âm điều trị tại vùng lưng bị đau sau khi điện châm với cường độ $0,5-1,2$ Wat/ $\mathrm{cm}^{2} \times 05$ phút//ần $\times 1$ lần/ngày x 20 ngày.

\subsection{Chỉ tiêu theo dõi và đánh giá}

- Đặc điểm chung của đối tượng nghiên cứu: tuổi, giới, nghề nghiệp, tính chất khởi phát.

- Lâm sàng: cải thiện mức độ đau theo thang điểm VAS, hiệu quả cải thiện độ giãn cột sống thắt lưng,hiệu quả cải thiện tầm vận động cột sống thắt lưng (các tư thế cúi, ưỡn, nghiêng)[1], [3], [4]. Các chỉ tiêu theo dõi và đánh giá được thực hiện tại các thời điểm bắt đầu nghiên cứu $\left(T_{0}\right)$, sau 10 ngày điều trị $\left(T_{1}\right)$, sau 20 ngày điều $\operatorname{trị~}\left(T_{2}\right)$.

- Đánh giá kết quả điều trị: so sánh điểm các chỉ tiêu các chỉ số VAS, độ giãn cột sống thắt lưng, tầm vận động cột sống thắt lưngtrước và sau điều trị, phân thành các loại kết quả tốt (tổng số điểm sau điêu trị giảm $>80 \%$ so với trước điều tri); Khá (tổng số điểm sau điều trị giảm $61-80 \%$ so với trước điều trị); Trung bình (tổng số điểm sau điều trị giảm 40-60\% so với trước điêu trị); Không kết quả (tổng số điểm sau điều trị giảm $<40 \%$ so với trước điêu trị)[1], [3], [4].

2.5. Xử lý số liệu. Số liệu được xử lý theo phương pháp thống kê y sinh học bằng phần mềm SPSS 16.0 for Windows. Các thuât toán được áp dụng: Tính tỷ lê phần trăm, tính số trung bình mẫu, độ lệch chuẩn, so sánh số trung bình theo thuât toán T-Student.

\section{KẾT QUẢ NGHIÊN CỨU}

\section{1. Đặc điểm chung các đối tượng nghiên cứu}

Bảng 1. Đặc điểm chungcác đối tượng nghiên cứu

\begin{tabular}{|c|c|c|c|c|c|c|}
\hline \multirow{2}{*}{\multicolumn{2}{|c|}{ Chỉ tiêu }} & \multicolumn{2}{|c|}{$N N C^{(1)}(n=30)$} & \multicolumn{2}{|c|}{$N Đ C^{(2)}(n=30)$} & \multirow[b]{2}{*}{$\mathbf{p}_{1-2}$} \\
\hline & & Số lượng & Tỷ lệ \% & Số Iượng & Tỷ lệ \% & \\
\hline \multirow{5}{*}{ Tuổi } & $20-29$ & 02 & 6,7 & 02 & 6,7 & $>0,05$ \\
\hline & $30-39$ & 05 & 16,7 & 06 & 20 & $>0,05$ \\
\hline & $40-49$ & 06 & 20 & 05 & 16,7 & $>0,05$ \\
\hline & $50-59$ & 11 & 36,7 & 10 & 33,3 & $>0,05$ \\
\hline & $>60$ & 06 & 20 & 07 & 23,3 & $>0,05$ \\
\hline \multirow{2}{*}{ Giới tính } & Nam & 12 & 40 & 13 & 43,3 & $>0,05$ \\
\hline & Nữ & 18 & 60 & 17 & 56,7 & $>0,05$ \\
\hline \multirow{2}{*}{$\begin{array}{c}\text { Nghề } \\
\text { nghiệp }\end{array}$} & Lao động trí óc & 17 & 56,7 & 14 & 46,7 & $>0,05$ \\
\hline & Lao động chân tay & 13 & 43,3 & 16 & 53,3 & $>0,05$ \\
\hline
\end{tabular}




\begin{tabular}{|c|c|c|c|c|c|c|}
\hline Tính chất & Đột ngột & 13 & 43,3 & 12 & 40 & $>0,05$ \\
\cline { 2 - 7 } khởi phát & Từ từ, tăng dần & 17 & 56,7 & 18 & 60 & $>0,05$ \\
\hline
\end{tabular}

Độ tuối mắc bệnh dưới 60 ở 2 nhóm chiếm tỷ lệ cao (80\% ở NNC và 76,7\% ở NĐC). Nữ giới mắc bệnh có xu hướng cao hơn nam giới (60\% ở NNC và 56,7\% ở NĐC). Tỷ lệ đối tượng lao động trí óc và lao động chân tay bị đau thắt lưng do THCS là tương đương. Bệnh đa phân khởi phát mang tính chất mạn tính(56,7\% ở NNC và $60 \%$ ở NĐC). Chưa nhận thấy khác biệt giữa các yếu tố tuổi, giới, nghề nghiệp và tính chất khởi phát giữa hai nhóm $(p>0,05)$.

\subsection{Kết quả điêu trị}

Bảng 2. Cải thiên mức đô đau (VAS) sau điều tri (điểm; $\bar{X}_{ \pm S D)}$

\begin{tabular}{|c|c|c|c|}
\hline Thời điểm & $\operatorname{NNC}^{(1)}(n=30)$ & $\operatorname{NDC}^{(2)}(n=30)$ & $\mathbf{p}_{1-2}$ \\
\hline $\mathrm{T}_{0}{ }^{(\mathrm{a})}$ & $6,32 \pm 1,04$ & $6,02 \pm 1,01$ & $>0,05$ \\
\hline $\mathrm{T}_{1}{ }^{(\mathrm{b})}$ & $3,10 \pm 0,76$ & $3,73 \pm 0,90$ & $>0,05$ \\
\hline $\mathrm{T}_{2}{ }^{(\mathrm{c})}$ & $0,70 \pm 0,69$ & $1,42 \pm 0,68$ & $<0,05$ \\
\hline$p$ & $\mathrm{p}_{a-b} ; \mathrm{p}_{\mathrm{a}-\mathrm{c}} ; \mathrm{p}_{\mathrm{b}-\mathrm{c}}<0,05$ & $\mathrm{p}_{\mathrm{a}-\mathrm{b}} ; \mathrm{p}_{\mathrm{a}-\mathrm{c} ;} ; \mathrm{p}_{\mathrm{b}-\mathrm{c}}<0,05$ & \\
\hline
\end{tabular}

Mức độ đau theo thang điếm VAS có xu hướng giảm dân qua các thời điếm theo dõi ở cả 2 nhóm. Khác biệt tại thời điểm trước điều trị $\left(T_{0}\right)$ và sau điều trị $\left(T_{1} ; T_{2}\right)$ có ý nghĩa thống kê $(p<0,05)$. Hiệu quả giảm đau sau 20 ngày điều trị của NNC tốt hơn NĐC $(p<0,05)$.

Bảng 3. Cải thiện độ giãn cột sống thắt lưng sau điều trị $\left(\mathrm{cm} ; \bar{X}_{ \pm S D}\right)$

\begin{tabular}{|c|c|c|c|}
\hline Thời điếm & $\operatorname{NNC}^{(1)}(n=30)$ & $N^{\prime} C^{(2)}(n=30)$ & $p_{1-2}$ \\
\hline $\mathrm{T}_{0}{ }^{(\mathrm{a})}$ & $1,18 \pm 0,58$ & $1,10 \pm 0,61$ & $>0,05$ \\
\hline$T_{1}{ }^{(b)}$ & $2,65 \pm 0,54$ & $2,22 \pm 0,65$ & $>0,05$ \\
\hline $\mathrm{T}_{2}{ }^{(\mathrm{c})}$ & $3,83 \pm 0,44$ & $2,43 \pm 0,50$ & $<0,05$ \\
\hline$p$ & $\mathrm{p}_{a-b ;} \mathrm{p}_{a-c ;} \mathrm{p}_{b-c}<0,05$ & $\mathrm{p}_{\mathrm{a}-\mathrm{c}}<0,05 ; \mathrm{p}_{\mathrm{a}-\mathrm{b}} ; \mathrm{p}_{\mathrm{b}-\mathrm{c}}>0,05$ & \\
\hline
\end{tabular}

Độ giãn cột sống thắt lưng trung bình ở cả hai nhóm BN tăng dân qua các thời điểm theo dõi và đánh giá, khác biệt trước và sau điều trị có ý nghĩa với $p<0,05$. Mức độ cải thiện độ giãn thắt lưng tại thời điểm sau 20 ngày điều trịở NNC tốt hơn NĐC $(p<0,05)$.

Bảng 4. Cải thiện tầm vận động cột sống thắt lưng sau điều trị (độ; $\left.{ }^{\bar{X}} \pm S D\right)$

\begin{tabular}{|c|c|c|c|c|}
\hline Động tác & Thời điếm & $N N C^{(1)}(n=30)$ & $\operatorname{NOC}^{(2)}(n=30)$ & $p_{1-2}$ \\
\hline \multirow{4}{*}{ Gấp } & $T_{0}^{(a)}$ & $53,30 \pm 7,31$ & $52,00 \pm 8,69$ & $>0,05$ \\
\hline & $\mathrm{T}_{1}(\mathrm{~b})$ & $68,09 \pm 8,51$ & $66,46 \pm 7,38$ & $>0,05$ \\
\hline & $\mathrm{T}_{2}(\mathrm{c})$ & $83,83 \pm 7,75$ & $77,20 \pm 6,23$ & $<0,05$ \\
\hline & $p$ & $\mathrm{p}_{a-b} ; \mathrm{p}_{\mathrm{a}-\mathrm{c}} ; \mathrm{p}_{\mathrm{b}-\mathrm{c}}<0,05$ & $\mathrm{p}_{\mathrm{a}-\mathrm{b}} ; \mathrm{p}_{\mathrm{a}-\mathrm{c}}<0,05 ; \quad \mathrm{p}_{\mathrm{b}-\mathrm{c}}>0,05$ & \\
\hline \multirow{4}{*}{ Ngưaa } & $T_{0}(\mathrm{a})$ & $17,76 \pm 3,16$ & $18,10 \pm 3,33$ & $>0,05$ \\
\hline & $\mathrm{T}_{1}(\mathrm{~b})$ & $21,60 \pm 2,52$ & $20,10 \pm 2,91$ & $>0,05$ \\
\hline & $\mathrm{T}_{2}(\mathrm{c})$ & $28,70 \pm 2,23$ & $25,06 \pm 3,48$ & $<0,05$ \\
\hline & $p$ & $\mathrm{p}_{a-b} ; \mathrm{p}_{a-c} ; \mathrm{p}_{\mathrm{b}-\mathrm{c}}<0,05$ & $\mathrm{p}_{\mathrm{a}-\mathrm{b}} ; \mathrm{p}_{\mathrm{a}-\mathrm{c}}<0,05 ; \quad \mathrm{p}_{\mathrm{b}-\mathrm{c}}>0,05$ & \\
\hline \multirow{4}{*}{ Nghiêng } & $T_{0}^{(a)}$ & $19,27 \pm 1,95$ & $19,07 \pm 1,91$ & $>0,05$ \\
\hline & $\mathrm{T}_{1}(\mathrm{~b})$ & $25,20 \pm 1,40$ & $23,00 \pm 4,45$ & $>0,05$ \\
\hline & $\mathrm{T}_{2}{ }^{(\mathrm{c})}$ & $29,86 \pm 4,15$ & $27,27 \pm 2,30$ & $<0,05$ \\
\hline & $\mathrm{p}$ & pa-b; $\mathrm{pa-c} ; \mathrm{p}_{\mathrm{b}-\mathrm{c}}<0,05$ & pa-b; $\mathrm{pa-c} ; \mathrm{p}_{\mathrm{b}-\mathrm{c}}<0,05$ & \\
\hline
\end{tabular}

Tâm vận động cột sống thắt lưng trung bình ở cả hai nhóm BN tăng dân qua các thời điểm theo dõi và đánh giá, khác biệt trước và sau điêu trị có ý nghĩa thống kê $(p<0,05)$. Mức độ cải thiện tầm vận động cột sống thắt lưngcác tư thế gấp, ngửa, nghiêng sau 20 ngày điều trịở NNC tốt hớn NĐC $(\dot{p}<0,05)$.

Bảng 5. Thay đổi tần số mạch, chi số huyết áp trước và sau điều trị

\begin{tabular}{|c|c|c|c|c|}
\hline Chỉ tiêu & Thời điếm & $N N C^{(1)}(n=30)$ & $\operatorname{NDC}^{(2)}(n=30)$ & $\mathbf{p}_{1-2}$ \\
\hline \multirow{3}{*}{ Mạch (lân/phút) } & $\mathrm{T}_{0}^{(\mathrm{a})}$ & $78 \pm 7,33$ & $77 \pm 6,1$ & $>0,05$ \\
\hline & $\mathrm{T}_{2}{ }^{(\mathrm{b})}$ & $78,33 \pm 5,16$ & $76,5 \pm 5,44$ & $>0,05$ \\
\hline & Pa-b & $>0,05$ & $>0,05$ & \\
\hline \multirow{3}{*}{$\begin{array}{l}\text { Huyết áp tâm thu } \\
(\mathrm{mmHg})\end{array}$} & $T_{0}(a)$ & $124,67 \pm 13,58$ & $123,83 \pm 14,43$ & $>0,05$ \\
\hline & $\mathrm{T}_{2}{ }^{(\mathrm{b})}$ & $124 \pm 9,69$ & $124,67 \pm 9,99$ & $>0,05$ \\
\hline & Pa-b & $>0,05$ & $>0,05$ & \\
\hline \multirow{3}{*}{$\begin{array}{l}\text { Huyết áp tâm } \\
\text { trương (mmHg) }\end{array}$} & $\mathrm{T}_{0}(\mathrm{a})$ & $79,83 \pm 10,38$ & $78,67 \pm 7,76$ & $>0,05$ \\
\hline & $\mathrm{T}_{2}{ }^{(\mathrm{b})}$ & $79,67 \pm 7,18$ & $77,67 \pm 6,12$ & $>0,05$ \\
\hline & $\mathbf{p}_{a-b}$ & $>0,05$ & $>0,05$ & \\
\hline
\end{tabular}


Tần số mạch, chỉ số huyết áp ở cả NNC và NĐC sau điều trị không khác biệt so với trước điều trị $(p>0,05)$.

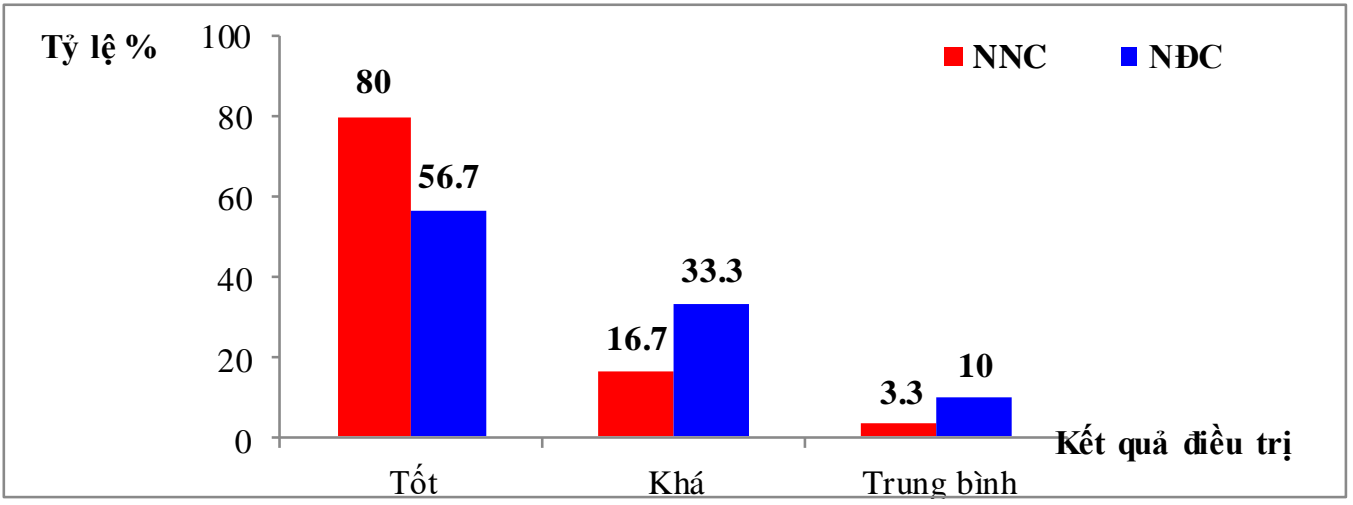

Biểu đồ 1. Hiệu quả chung sau 20 ngày điều trị

Sau 20 ngày điều trị, không có trường hợp nào không đáp ứng với điều trị. Tỷ lệ BN đạt kết quả điều trị tốt ở NNC cao hơn có ý nghĩa so với NĐC $(p<0,05)$.

\section{BÀN LUẬN}

4.1. Đặc điểm chung các đối tượng nghiên cứu. Về tuổi mắc bệnh, kết quả cho thây $80 \%$ BN NNC và $76,7 \%$ BN NĐC có tuổi dưới 60.Đây là nhómngười đang trong độ tuổi lao động do vậy đau thắt lưng do THCS gây ảnh hưởng nhiêu chất lượng, hiệu suất lao động và sinh hoạt của người bệnh. Kết quả này phù hợp với cơ chế bệnh sinh của THCS thắt lưng, đó là do sự chịu đựng tải trọng thường xuyên của cột sống dẫn tới thoái hóa dây chằng cột sống, đặc biệt ở người trong độ tuổi lao động[1]. Kết quả này cũng cho thấy đau thắt lưng do THCS có xu hướng trẻ hóa, do vậy điều trị và điều trị dự phòng đối với bệnh lý này là vấn đề cần được quan tâm, đây cũng là nhận xét của nhiều tác giả khi đánh giá tình trạng đau thắt lưng do THCS[3],[4], [8].

Về giới tính, tỷ lệ nữ giới mắc bệnh cao hơn nam giới ( $60 \%$ ở NNC và $56,7 \%$ ở NĐC). Nhiều nghiên cứu cho rằng tỷ lệ nữ bị THCS thắt lưng nhiều hơn nam do sự thay đổi hormon, đặc biệt sự thiếu hụt hormon estrogen sau mãn kinh, làm giảm khả năng hấp thu canxi - thành phần quan trọng tham gia cấu tạo đĩa đệm và xương khớp. Mặt khác cũng có thể do phụ nữ có ý thức quan tâm tới sức khỏe bản thân hơn nên tới khám và điều trị ngay khi mới xuất hiện triệu chứng bệnh[1],[3], [4].

Về tính chất nghề nghiệp, đa phần các nghiên cứu cho thây tỷ lệ BN thuộc nhóm lao động chân tay mắc bệnh cao hơn so với lao động trí óc do đây là những đối tượng thường xuyên mang vác, kéo đẩy vật nặng khồng đúng tư thế hoặc mang vác nặng từ khi khung xương chưa được định hình và hoàn thiên khiến cột sống thắt lưng bị tổn thương, cấu trúc cột sống bị thay đổi, mô xương, cơ, dây chằng bị biến đổi và dễ bị thoái hóa[1], [2]. Tuy nhiên kết quả nghiên cứu của chúng tôi cho thấy tỷ lê lao động trí óc và lao động chân tay bị đau thắt lưng do THCS là tương đương, điều này cho thấy nguyên nhân gây bệnh không chỉ đến từ công việc nặng nhọc mà còn đến từ những công việc nhẹ nhàng nhưng thường xuyên làm việc ở tử thế cố định trong thời gian dài, ít vận động, là một trong những yếu tố làm thúc đẩy nhanh quá trình THCS trong đó có cột sống thắt lưng. Đây cũng là nhận định của một số tác giả khi nghiên cứu về bệnh lý THCS thắt lưng[3], [4], [8]...

$56,7 \%$ BN NNC và $60 \%$ BN NĐC khởi phát từ từ, mạn tính. Điều này cho thấy THCS thắt lưnglà bệnh lý mang tính chất dai dẳng kéo dài, gây ảnh hưởng nhiều tới chất lượng cuộc sống của người bệnh. Đồng thời cũng cho thấy người bênh chưa thực sự hiểu và quan tâm tới bênh lý THCS thắt lưng, thường cố chịu đựng hoặc do ngại tớikhám và điều trị tại các cơ sở y tế mà tự mua thuốc điều trị, chỉ chấp nhận điều trị tại cớ sở y tế khi không còn lựa chọn khác. Do vậy việc tăng cường giáo dục cộng đồng về THCS thắt lưng là cân thiết và có ý nghĩa[1], [3], [4], [8].

Chưa nhận thây khác biệt giữa các yếu tố tuổi, giới, nghề nghiệp và tính chất khời phát giữa NNC và NĐC. Kết quả này phản ánh sự khách quan khi tiến hành nghiên cứu.

4.2. Kết quả điều trị. Trong THCS thắt lưng, đau là triệu chứng chính khiến người bệnh phải tới bệnh viện khám và điều trị̣[1]. Để đánh giá hiệu quả điều trị, cần phải đánh giá mức độ 
giảm đau của BN, VAS là thang điểm thông dụng để đánh giá mức độ đau được nhiều nghiên cứu lựa chọn [2], [3], [4]... Kết quả nghiên cứu cho thấy mức độ đau theo thang điểm VAS có xu hướng giảm dần qua các thời điểm theo dõi, khác biệt giữa thời điểm trước điều trị và sau điêu trị có ý nghĩa thống kê,hiệu quả giảm đau sau 20 ngày điêu trị của NNC tốt hơn có ý nghĩa so với NĐC. Kết quả này chứng tỏ điện châm đơn thuần hoặc kết hợp điện châmvà siêu âm điều trị đã có hiệu quả giảm đau thắt lưng do THCS. Về lý luận, điện châmcó thể thông qua tác động tại chỗ, phản ứng tiết đoạn và phản ứng toàn thân kích thích phản ứng cơ thể làm giảm hàm lượng Cathecholamin, tăng hàm lượng Acetylcholin và làm sản sinh Endorphin nội sinh, từ đó đạt được hiệu quả giảm đau[3]. Siêu âm điều trị là phương pháp vật lý thông qua các hiệu ứng nhiệt, hiêu ứng cơ hoc và hóa học có tác dụng trực tiếp lên các thụ cảm thể thần kinh, giãn cơ, cải thiện tuần hoàn, giảm phù nề, giảm viêm do đó giúp giảm đau nhanh [5], [6]. Như vậy,có thể nhận định điện châm kết hợp siêu âm điêu trịcó tác dụng giảm đau rõ rệt.

Kết quả nghiên cứu cho thấy độ giãn cột sống thắt lưng trung bình, tầm vận động cột sống thắt lưng trung bình các tư thế ở cả hai nhóm BN đều cải thiện qua các thời điểm đánh giá, khác biệt có ý nghĩa thống kê. Mức độ cải thiện của các chỉ tiêu này sau 20 ngày điêu trịu NNC tốt hơn có ý nghĩa so với NĐC (bảng 3, bảng 4). Kết quả này tương tự với nghiên cứu của George K (2013), Phạm Thị Ngọc Bích (2016), Nguyễn Vinh Quốc (2018)[3], [4], [6]. Theo nhận định của chúng tôi, kết quả này là do phương pháp kết hợp điện châm vàsiêu âm điều trịđã đạt hiệu quả điều trị kép, một mặt bản thân điện châm giúp thúc đẩy quá trình sản sinh Endorphin nội sinh có tác dụnggiảm đau, mặt khác lại nhờhiệu ứng cơ học của siêu âm điêu trị làm giãn cơ, tăng tính thấm màng tế bào, tách rời các sợi collagen và làm mềm chất kết dính tại tổ chức..., từ đó giúp ích cho quá trình phục hồi các tổn thương một cách nhanh chóng và hiệu quả [5].

Sau 20 ngày điều trị, tỷ lệ BN đạt kết quả điều trị tốt NNC $(80 \%)$, cao hớn có ý nghĩa so với NĐC $(56,7 \%)$. Kết quả này cao hơn Phạm Thị Ngọc Bích, Nguyễn Vinh Quốc khi kết hợp điện châm với thuốc YHCT điều trị đau thắt lưng do THCS [3], [4]. Theo chúng tôi, với tác dụng điều khí, giúp lưu thông khí huyết nơi kinh lạc bị bế tắc, thúc đẩy quá trình sản sinh Endorphin nội sinh của điện châm kết hợp với tác dụng giãn cớ, cải thiện tuần hoàn, giảm phù nề, giảm viêm của siêu âm điều trị đã góp phần tạo nên hiệu quả điêu trị tốt ở các BNNNC cao hơn có ý nghĩa so với sử dụng điện châm đơn thuần.

Trong quá trình thực hiện nghiên cứu, chúng tôi nhận thấyđiện châm đơn thuần hoặc kết hợp điện châmvà siểu âm điều trị không ảnh hưởng tới tần số mạch, chỉ số huyết áptrên các đối tượng tham gia nghiên cứu. Điều cho thấy đây là những phương pháp điều trị an toàn, mặt khác cũng cho thấy trình độ và năng lực của kỹ thuật viên Bệnh viện Châm cứu Trung ương khi thực hiện các dịch vụ kỹ thuật chuyên ngành.

\section{KẾT LUÂ̂N}

Điện châm kết hợp siêu âm điều trị có hiệu quả tốt trong điều trị đau thắt lưng do thoái hóa cột sống. Cải thiện mức độ đau theo thang điểm VAS, cải thiện độ giãn cột sống thắt lưng, cải thiện tầm vận động cột sống thắt lưng tốt hơn có ý nghĩa so với trước điêuu trị vàtốt hơnso với nhóm đối chứng dùng phương pháp điện châm đơn thuần. $80 \%$ bệnh nhân đạt kết quả tốt sau 20 ngày điều trị.

Điện châm kết hợp siêu âm điều trịkhông ảnh hưởng tới tần số mạch, chỉ số huyết áp của các bệnh nhân nghiên cứu.

\section{TÀI LIÊU THAM KHẢO}

1. Hồ Hữu Lương (2012). Đau thắt lưng và thoát vị đĩa đệm, NXB Y học, Hà Nội.

2. Xie F., Zhou H., Žhao W. (2017). Acomparative study on the mechanical behavior of intervertebral disc using hyperelastic finite element model. Technol Health Care, Preprint (Prepint), 1-11.

3. Phạm Thi Ngọc Bích, Lê Thành Xuân (2016). Hiểu quả lâm sàng trong điều trị đau thắt lưng do thoái hóa cột sống bằng điện trường châm kết hợp với bài thuốc độc hoạt tang ký sinh. Tạp chí nghiên cứu y hoc, 103(5), 32-39.

4. Nguyê̂n Vinh Qưốc, Nguyê̂n Đức Minh (2018). Điện châm kết hợp Hoàn chỉ thống điêuu trị thoái hóa cột sống thắt lưng. Tạp chí Y học Việt nam, $12(1 \& 2), 130-134$.

5. Hoc viện Quân y - Bộ môn vật lý trị liệu và Phục hổi chức năng (2014). Siêu âm điêu trị. Vât lý trị liệu và Phục hồi chức năng, NXB Quân độ̉i nhân dần, Hà Nội, 110-114.

6. George K., Mathew D. (2013). Design and evaluation of a wearable self-apple therapeutic ultrasound device for chronic myofacial pain. Ultrasound in Medicine \& Biology, 39(8), 1429-1439.

7. Bô Y tế (2013). Quyết định số 792 /QĐ-BYT ngà̀y 12 tháng 3 năm 2013 về việc ban hành Hướng dẫn Quy trình kỹ thuật khám bệnh, chữa bệnh chuyên ngành Châm cưu.

8. Nguyễn Vinh Quốc, Nguyễn Thị Huệ (2020). Hiệu quả điều trị thoái hóa cột sống thắt lưng bằng điện xung kết hợp bài thuốc tam tý thang. Tạp chí Ý học Việt nam, 488(1), 221-224. 